\title{
Interpreting aerosol lifetimes using the GEOS-Chem model and constraints from radionuclide measurements
}

\author{
B. Croft ${ }^{1}$, J. R. Pierce ${ }^{1,2}$, and R. V. Martin ${ }^{1,3}$ \\ ${ }^{1}$ Department of Physics and Atmospheric Science, Dalhousie University, Halifax, Canada \\ ${ }^{2}$ Colorado State University, Fort Collins, CO, USA \\ ${ }^{3}$ Harvard-Smithsonian Center for Astrophysics, Cambridge, MA, USA
}

Correspondence to: B. Croft (croft@mathstat.dal.ca)

Received: 30 October 2013 - Published in Atmos. Chem. Phys. Discuss.: 10 December 2013

Revised: 12 February 2014 - Accepted: 12 March 2014 - Published: 30 April 2014

\begin{abstract}
Aerosol removal processes control global aerosol abundance, but the rate of that removal remains uncertain. A recent study of aerosol-bound radionuclide measurements after the Fukushima Daiichi nuclear power plant accident documents ${ }^{137} \mathrm{Cs}$ removal (e-folding) times of 10.0-13.9 days, suggesting that mean aerosol lifetimes in the range of 3-7 days in global models might be too short by a factor of two. In this study, we attribute this discrepancy to differences between the e-folding and mean aerosol lifetimes. We implement a simulation of ${ }^{137} \mathrm{Cs}$ and ${ }^{133} \mathrm{Xe}$ into the GEOS-Chem chemical transport model and examine the removal rates for the Fukushima case. We find a general consistency between modelled and measured e-folding times. The simulated ${ }^{137} \mathrm{Cs}$ global burden e-folding time is about 14 days. However, the simulated mean lifetime of aerosol-bound ${ }^{137} \mathrm{Cs}$ over a 6month post-accident period is only 1.8 days. We find that the mean lifetime depends strongly on the removal rates in the first few days after emissions, before the aerosols leave the boundary layer and are transported to altitudes and latitudes where lifetimes with respect to wet removal are longer by a few orders of magnitude.

We present sensitivity simulations that demonstrate the influence of differences in altitude and location of the radionuclides on the mean lifetime. Global mean lifetimes are shown to strongly depend on the altitude of injection. The global mean ${ }^{137} \mathrm{Cs}$ lifetime is more than one order of magnitude greater for the injection at $7 \mathrm{~km}$ than into the boundary layer above the Fukushima site. Instantaneous removal rates are slower during the first few days after the emissions for a free tropospheric versus boundary layer injection and this strongly controls the mean lifetimes. Global mean aerosol
\end{abstract}

lifetimes for the GEOS-Chem model are 3-6 days, which is longer than that for the ${ }^{137} \mathrm{Cs}$ injected at the Fukushima site (likely due to precipitation shortly after Fukushima emissions), but similar to the mean lifetime of 3.9 days for the ${ }^{137} \mathrm{Cs}$ emissions injected with a uniform spread through the model's Northern Hemisphere boundary layer. Simulated efolding times were insensitive to emission parameters (altitude, location, and time), suggesting that these measurementbased e-folding times provide a robust constraint on simulated e-folding times.

Despite the reasonable global mean agreement of GEOSChem with measurement e-folding times, site by site comparisons yield differences of up to a factor of two, which suggest possible deficiencies in either the model transport, removal processes or the representation of ${ }^{137} \mathrm{Cs}$ removal, particularly in the tropics and at high latitudes. There is an ongoing need to develop constraints on aerosol lifetimes, but these measurement-based constraints must be carefully interpreted given the sensitivity of mean lifetimes and e-folding times to both mixing and removal processes.

\section{Introduction}

Aerosols have important impacts on global air quality (van Donkelaar et al., 2010), human health (Dockery et al., 1993; Pope III et al., 2009) and climate (Twomey, 1991; Charlson et al., 1992; Lohmann and Feichter, 2005). Simulations of aerosol three-dimensional distributions with global models play an essential role in understanding and quantifying these effects. Aerosol lifetimes control regional and global aerosol 
abundance. However, as noted by Textor et al. (2006), global aerosol lifetimes depend on a number of processes and parameters, including their source and sink functions, particle sizes and spatial dispersion, which have a wide diversity between models. Studies of radionuclide removal rates, such as after accidental emissions, provide an important constraint on aerosol removal times since certain radionuclides such as ${ }^{137} \mathrm{Cs}$ attach directly to aerosols upon emission and share their removal (Cambray et al., 1987; Schwartz, 1996). Recently, Kristiansen et al. (2012) presented e-folding times of measured aerosol-bound ${ }^{137} \mathrm{Cs}$ and ${ }^{131} \mathrm{I}$ surface layer activity concentrations at remote, global atmospheric sites after the March 2011 Fukushima Daiichi nuclear power plant (FDNPP) accident as a constraint on atmospheric removal times for global models. Based on this constraint, Kristiansen et al. (2012) suggest that global models with mean aerosol lifetimes of 3-7 days may underestimate lifetimes by as much as a factor of two.

However, as discussed by Kristiansen et al. (2012) the measured e-folding time and the mean lifetime in models may not be directly comparable since the measurements were made far from the accident site and removal rates are expected to differ between the boundary layer (such as initially after emission) and free troposphere. In the event that the rate of removal is other than first order with a constant coefficient, e-folding times and mean lifetimes are expected to diverge (Schwartz, 1979). In this study, we quantify the extent of this divergence for the FD-NPP accident case. We implement a simulation of ${ }^{137} \mathrm{Cs}$ and ${ }^{133} \mathrm{Xe}$ into the GEOS-Chem chemical transport model (Bey et al., 2001) and examine the lifetime of ${ }^{137} \mathrm{Cs}$ for the Fukushima case. Our goal is to document, compare, and explain differences between mean aerosol lifetimes and e-folding times over several months following the FD-NPP accident.

Additionally, a set of sensitivity simulations are presented, which examine the dependence of mean lifetimes and efolding times on the altitude and location of the aerosolbound ${ }^{137} \mathrm{Cs}$ and the time after emission, as well as on the emission parameters (altitude, location and time). Previous work by Giorgi and Chameides (1986) with an earlygeneration climate model showed that aerosol mean lifetimes can vary by an order of magnitude depending on whether the aerosols have a source at the surface or in the upper troposphere. This was hypothesized to explain the wide variety of measurement-based radionuclide lifetimes when grouped according to their source location. In this study, we use the GEOS-Chem model to consider the impact of boundary layer versus free troposphere source locations on ${ }^{137} \mathrm{Cs}$ lifetimes.

Aerosol lifetimes depend on the removal of aerosols from the atmosphere by both dry and wet deposition processes (Rasch et al., 2000; Textor et al., 2006; Croft et al., 2009, 2010, 2012). The aerosol-bound radionuclides emitted after the FD-NPP accident attach primarily (by mass) to aerosols in the size range of the accumulation mode, similar to sulfate (radii $0.05-0.5 \mu \mathrm{m}$ ) (Kaneyasu et al., 2012) due to the peak of the aerosol surface area distribution for this mode, and thus undergo similar removal processes. These aerosols are removed primarily by wet scavenging processes, which occur both in and below clouds. As a result, ${ }^{137} \mathrm{Cs}$ surface layer concentration measurement e-folding times of 10.0 13.9 days primarily characterize accumulation mode aerosol wet removal rates since ${ }^{137} \mathrm{Cs}$ has a long half-life (about 30 years) and dry deposition is a relatively minor sink for aerosols in this size range. Measurements taken remote to the emissions site also characterize free tropospheric lifetimes since long-range transport generally occurs above the boundary layer, but obviously aerosols mix back into the boundary layer, or rain out of the free troposphere to be removed.

For this investigation, we implement into GEOS-Chem the radionuclide emission data set of Stohl et al. (2012), who prepared the data set by improving first guess estimates of ${ }^{137} \mathrm{Cs}$ and ${ }^{133} \mathrm{Xe}$ emissions from the FD-NPP using the atmospheric transport model FLEXPART combined with concentration and deposition measurement data from several dozen sites. The following sections present the lifetime definitions used for this study and give the GEOS-Chem model description. Section 4 provides our lifetime results and discussion. We compare to Comprehensive Nuclear Test-Ban Treaty Organization (CTBTO) site surface layer activity concentration $\left({ }^{137} \mathrm{Cs} /{ }^{133} \mathrm{Xe}\right.$ ratio) e-folding times presented by Kristiansen et al. (2012). We then go on to explain differences between the simulated mean lifetimes and e-folding times during the six months after the nuclear accident. Section 4 also includes the results of our sensitivity simulations, which examine the dependence of mean lifetimes and e-folding times on injection heights, altitude and location of the radionuclides, and the time after emission.

\section{Lifetime definitions}

Several definitions are used to describe aerosol lifetimes in the Earth's atmosphere. In any given domain, the species mass balance may be described as

$\frac{d C(t)}{d t}=S(t)-\frac{C(t)}{\tau(t)}$,

where $C(t)$ is the species abundance at time $t, S(t)$ is the source rate, and $\tau(t)$ is the removal timescale. In a steady state, where aerosol sources are continuous and there is a quasi-equilibrium between sources and sinks such that the mean species abundance is constant in time, the global and annual mean steady-state aerosol lifetime $\tau_{s s}$ is defined as

$\tau_{s s}=\frac{\bar{C}}{\bar{D}}$

and $\bar{C}$ is the mean abundance and $\bar{D}$ is the deposition rate (equal to the source rate) over the time period and chemical loss is negligible. 
In the case of an emission pulse (either instantaneous or over a short period) followed by a removal period considerably longer than the pulse, the mean lifetime can be similarly defined using the integral form of Eq. (1) and assuming $S(t)=0$ for the time period of integration. For example, over a period of six months $(6 \mathrm{mo})$, in the case that $\tau(t)$ is time dependent, one can approximate the integral and define the 6-month mean lifetime as

$\tau_{6 \mathrm{mo}}=\frac{\sum_{t=0}^{t=6 \mathrm{mo}} C(t)}{\sum_{t=0}^{t=6 \mathrm{mo}} D(t)}$,

where $C(t)$ is the global aerosol mass burden at time $t, D(t)$ is the sink term, representing the absolute aerosol mass loss rate during a timestep $(\Delta t)$. This is expected to be a close approximation to the steady-state mean lifetime if the mean is taken over a period of time extending considerably longer than the emission pulse, starting at the onset of the burden decrease, and using timesteps that are short relative to time period for the integration.

The e-folding time, $\tau_{e}$ is also commonly used to describe the decrease in aerosol burden following an emission pulse. Assuming that $\tau$ is independent of time, Eq. 1 can be integrated without need for approximation. Thus, $\tau_{e}$ is defined as

$\tau_{e}=\frac{-t_{i}}{\ln \left(\frac{C\left(t_{i}\right)}{C\left(t_{o}\right)}\right)}$,

where $C\left(t_{o}\right)$ is the initial aerosol mass burden at time $t_{o}$ and $t_{i}$ is the time since $t_{o}$.

The instantaneous lifetime can be used to characterize exponentially decreasing aerosol burden with a time dependent $\tau(t)$ under the quasi-steady-state assumption that $\tau(t)$ is constant over short time periods, which allows explicit integration to yield a form similar to the equation for $\tau_{e}$. For an exponential decrease, we may define the instantaneous lifetime as

$$
\tau_{\text {instant }}=\frac{t_{i}-t_{i-1}}{-\ln \left(\frac{C\left(t_{i}\right)}{C\left(t_{i-1}\right)}\right)},
$$

where $t_{i}$ and $t_{i-1}$ are adjacent timesteps. $\tau_{\text {instant }}$ is equivalent to $\tau_{e}$ if $\tau_{e}$ is time independent. The differences between these characterizations of aerosol lifetime are examined and quantified in the following sections.

\section{Model description}

We use the GEOS-Chem chemical transport model version 9-01-03 (www.geos-chem.org) to interpret aerosol-bound ${ }^{137} \mathrm{Cs}$ and ${ }^{133} \mathrm{Xe}$ activity concentrations following the FDNPP accident. The model is driven by assimilated meteorology from the Goddard Earth Observing System (GEOS5) of the NASA Global Modeling and Assimilation Office (GMAO). The horizontal resolution used for this study is $2^{\circ} \times 2.5^{\circ}$, with 47 vertical layers (model lid at $0.01 \mathrm{hPa}$ ). The time period simulated is from 1 March 2011 to 1 September $2011 .{ }^{137} \mathrm{Cs}$ and ${ }^{133} \mathrm{Xe}$ are added to the radionuclide simulation described in Liu et al. (2001). The model uses the advection scheme of Lin and Rood (1996) and the moist convective mixing scheme of Allen et al. (1997) applied to mass fluxes from the relaxed Arakawa-Schubert algorithm (Arakawa and Schubert, 1974; Moorthi and Suarez, 1992). The standard GEOS-Chem model includes a bulk aerosol mass simulation of the sulfate-ammonium-nitrate system (Park et al., 2004), as well as sea salt (Alexander et al., 2005; Jaeglé et al., 2011), dust (Fairlie et al., 2007, 2010) and carbonaceous aerosols (Park et al., 2003; Liao et al., 2007; Henze et al., 2008; Wang et al., 2011). Carbonaceous aerosols are considered as either hydrophobic or hydrophilic, with a fixed e-folding time for conversion from the hydrophobic to hydrophilic state. Hydrophilic aerosols are removed by in-cloud rainout and all aerosols are subject to dry deposition and below cloud washout by precipitation. The original aerosol dry and wet deposition scheme in GEOS-Chem is described in Bey et al. (2001), and Liu et al. (2001). Modifications to the wet deposition scheme described in Wang et al. (2011) are used for this study.

\subsection{Radionuclide simulations}

We implemented in the GEOS-Chem model the emissions of Stohl et al. (2012) for ${ }^{137} \mathrm{Cs}$ (an aerosol-bound radionuclide) and ${ }^{133} \mathrm{Xe}$ (a noble gas with half-life period of 5.25 days) in the GEOS-Chem model. The total emissions for the FD-NPP accident are $36.6 \pm 16.5 \mathrm{PBq}{ }^{137} \mathrm{Cs}$ and $15.3(-3.1,+3.0)$ $\mathrm{EBq}{ }^{133} \mathrm{Xe}$. The model is initialized with an arbitrary small concentration for both ${ }^{137} \mathrm{Cs}$ and ${ }^{133} \mathrm{Xe}$ and the Stohl et al. (2012) emissions are introduced after a 1-month spin up period. ${ }^{133} \mathrm{Xe}$ is treated as a passive tracer and does not undergo any wet or dry removal processes. To allow direct comparison with published decay-corrected surface layer ${ }^{133} \mathrm{Xe}$ activity concentration measurement e-folding times presented by Kristiansen et al. (2012), we do not allow radioactive decay of ${ }^{133} \mathrm{Xe}$. The long ${ }^{137} \mathrm{Cs}$ half-life of about 30 years allows radioactive decay to be neglected for the time frame of this study.

We parameterize ${ }^{137} \mathrm{Cs}$ to undergo the same dry and wet deposition processes as accumulation mode sulfate aerosols. For all simulations presented in our study, the ${ }^{137} \mathrm{Cs}$ is assumed to be apportioned entirely into the accumulation mode size range for the purposes of removal. To evaluate the validity of this assumption, we used the GEOS-Chem aerosol fields simulated at the Fukushima Daiichi site during the time of the ${ }^{137} \mathrm{Cs}$ emissions to determine the condensation rates to both accumulation and coarse aerosol modes at the time of emission. This was done assuming that the condensation rates to each aerosol mode are dependent on the Fuchs-corrected aerosol surface area. At most, $20 \%$ of the ${ }^{137} \mathrm{Cs}$ could be apportioned to the coarse mode. An additional 
Table 1. Summary of the simulations conducted for this study.

\begin{tabular}{|c|c|}
\hline Simulation name & Description \\
\hline CTL & $\begin{array}{l}\text { Emissions of Stohl et al. (2012) implemented in GEOS-Chem simulation } \\
\text { for March } 2011 \text { to September } 2011\end{array}$ \\
\hline USFC & $\begin{array}{l}\text { Total emissions of Stohl et al. (2012) uniformly spread throughout Northern Hemisphere } \\
\left(0-90^{\circ} \mathrm{N}, 180^{\circ} \mathrm{W}-180^{\circ} \mathrm{E}\right) \text { in an instantaneous pulse injection in model surface layer } \\
\text { on } 11 \text { March } 2011\end{array}$ \\
\hline U5K & Same as USFC but instantaneous injection into model layer at $5 \mathrm{~km}$ above ground level \\
\hline $\mathrm{U} 7 \mathrm{~K}$ & Same as USFC but instantaneous injection into model layer at $7 \mathrm{~km}$ above ground level \\
\hline
\end{tabular}

sensitivity simulation (not shown) indicated that the global mean burden and CTBTO site surface layer concentrations remained within $15 \%$ of our simulations with $100 \%$ of the ${ }^{137} \mathrm{Cs}$ apportioned to the accumulation mode at the time of emission.

Table 1 summarizes the simulations conducted to examine the sensitivity of the aerosol removal times to injection altitude and location, to the altitude and location of the radionuclides, and to the time after emission. The CTL simulation injects the emissions in layers up to $3 \mathrm{~km}$ over the Fukushima Daiichi power plant location, as described in Stohl et al. (2012). The emissions are ongoing for about 40 days, with the majority of the emissions in the first week after the earthquake. The USFC simulation assumes the total emissions of Stohl et al. (2012) are injected with a uniform distribution across the entire Northern Hemisphere and into the surface model layer with a one-time instantaneous pulse injection on 11 March 2011. The U5K and U7K simulations are similar, except that the emissions are injected in the atmospheric layer at $5 \mathrm{~km}$ and $7 \mathrm{~km}$, respectively.

\section{Results}

\subsection{Simulated global lifetimes}

Figure 1 shows the geographic distribution of the simulated ${ }^{137} \mathrm{Cs}$ burden for the control (CTL) simulation on days 10 and 20 after the onset of the nuclear accident. Qualitatively our results are quite similar to those presented by Stohl et al. (2012). The ${ }^{137} \mathrm{Cs}$ plumes encircle the Northern Hemisphere after about 10 days and ${ }^{137} \mathrm{Cs}$ mixes throughout the Northern Hemisphere after about 3 weeks. CTBTO sites where ${ }^{137} \mathrm{Cs}$ and ${ }^{133} \mathrm{Xe}$ activity concentration measurements are taken are indicated by the red circles. Kristiansen et al. (2012) give ${ }^{137} \mathrm{Cs} /{ }^{133} \mathrm{Xe}$ surface layer concentration ratio e-folding times at these sites that are compared to our simulations in the following section. ${ }^{137} \mathrm{Cs}$ activity concentrations at all of these sites were strongly influenced by the radionuclide plumes travelling out from the FD-NPP site, which is indicated by the black circle.

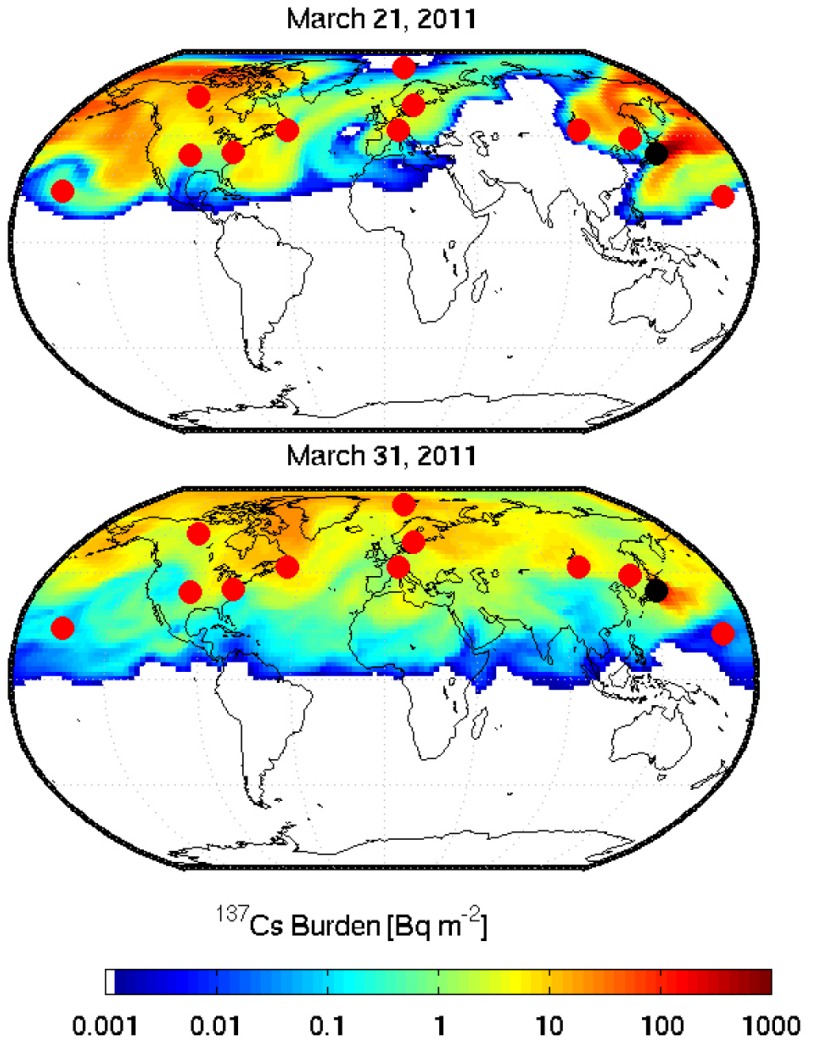

Fig. 1. Geographic distribution of ${ }^{137} \mathrm{Cs}$ burden on 21 March 2011 and 31 March 2011 for the control simulation (CTL) of the GEOSChem model using the emissions of Stohl et al. (2012). The accident site is indicated by a black dot and Comprehensive Nuclear Test-Ban Treaty Organization (CTBTO) measurements sites are indicated by red dots.

Figure 2 shows the simulated global ${ }^{137} \mathrm{Cs}$ burden as a function of days after the March 11, 2011 earthquake for simulation CTL (black symbols). Equations 3 and 4 are used to calculate the global mean lifetime over the 6 month simulation and the e-folding time (fit between days 20 and 80) for the global burden. For the CTL simulation, the global mean aerosol-bound ${ }^{137} \mathrm{Cs}$ lifetime is about 1.8 days and the efolding time for the global burden is 14.1 days. Thus, there is 


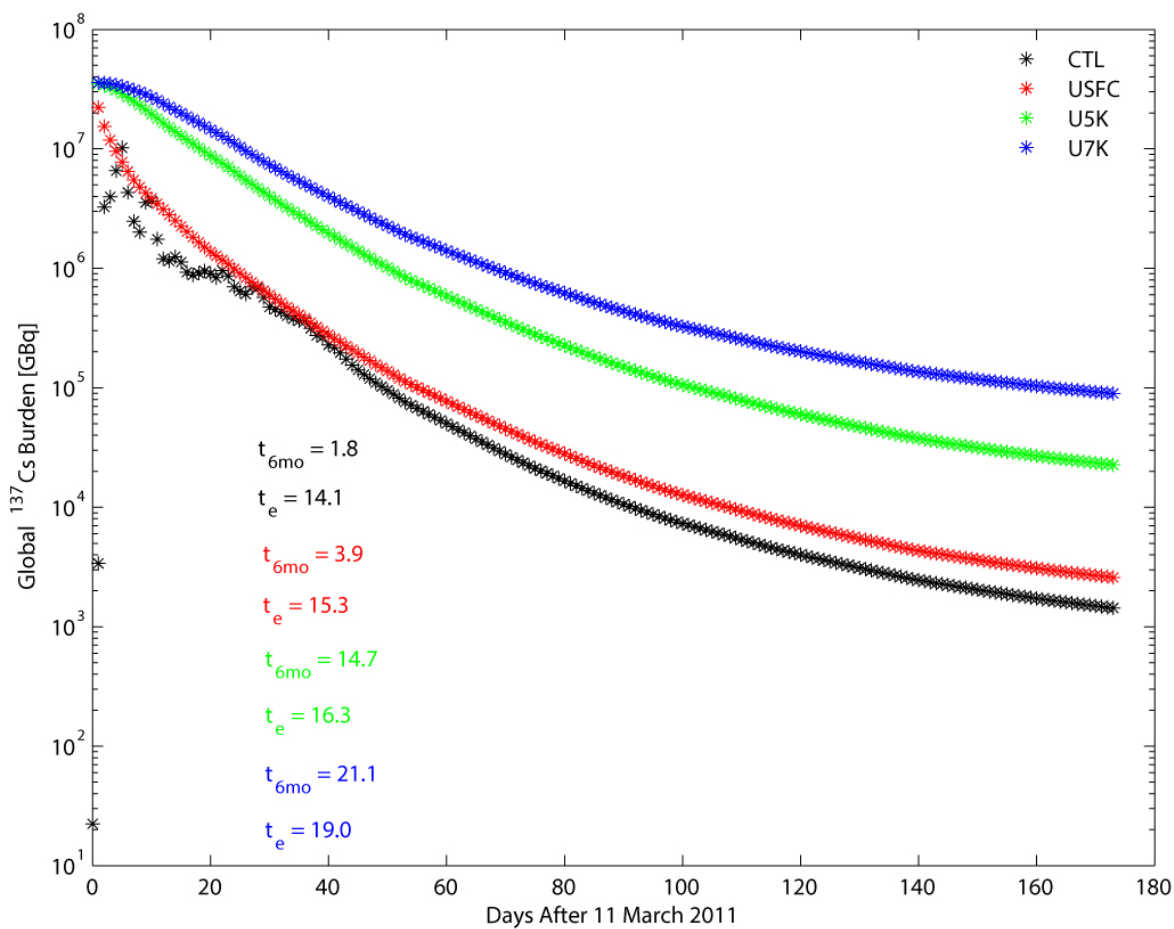

Fig. 2. Global ${ }^{137} \mathrm{Cs}$ burden for the four GEOS-Chem simulations of this study described in Table 1. The global 6-month mean lifetime $\left(\tau_{6 \mathrm{mo}}\right)$ and the e-folding time $\left(\tau_{\mathrm{e}}\right)$ in days fit over days 20 to 80 after 11 March 2011 are color coded to match the four simulations as indicated by the legend.

almost one order-of-magnitude difference between these two characterizations of lifetime. The mean lifetime of aerosolbound ${ }^{137} \mathrm{Cs}$ is strongly controlled by the removal of the majority of the global burden, which occurs in the first few days after the emissions and before the radionuclides have left the boundary layer and entered the free troposphere. This is evidenced by the one order-of-magnitude reduction in the global burden within about one week after the onset of emissions.

Figure 2 also shows the global ${ }^{137} \mathrm{Cs}$ burden for the three sensitivity simulations. Simulation USFC with surface layer injection throughout the Northern Hemisphere and the CTL simulation have similar global burdens. Differences in the global burden between simulation CTL and simulation USFC in the first few days can be attributed to the efficient aerosol removal by rain events close to the FD-NPP site during that time for simulation CTL. This occurs since a larger portion of the global burden resides near sites of rain events for simulation CTL than for simulation USFC. These differences in the spatial distribution of the ${ }^{137} \mathrm{Cs}$ and precipitation yield a greater global mean removal strength over the first few weeks for simulation CTL relative to USFC. The emissions for simulation USFC were emitted into regions of the Northern Hemisphere with less efficient wet removal (poleward and arid zones). This slower removal in the first few days after the emissions yields a slightly larger global burden (by about a factor of two) after 6 months. After 20 days, the ${ }^{137} \mathrm{Cs}$ is reaching a quasi-steady-state gradient of concentration throughout the Northern Hemisphere troposphere for both simulations, and thereafter the rate of decrease of the global burden is similar between simulations CTL and USFC.

Figure 2 also shows that for simulations U5K and U7K, the global burden decreases more slowly during the first two weeks than for simulations CTL and USFC. This decrease is slowest for simulation U7K. For these higher altitudes of injection, the aerosol-bound ${ }^{137} \mathrm{Cs}$ is already higher in the free troposphere, where removal is less efficient, and the particles must mix down towards the boundary layer before their removal rates are comparable to the surface-injection simulations.

The residual global burden 6 months after 11 March 2011 (shown in Fig. 2) increases with the altitude of the injection. At six months, there is a two order-of-magnitude difference in burden between simulations CTL and U7K. This residual burden depends on the removal rates in the first three weeks after the onset of emissions, before the aerosol-bound ${ }^{137} \mathrm{Cs}$ reaches a quasi-steady-state gradient of concentration in the Northern Hemisphere troposphere. Scavenging rates are faster in the first few days after the onset of emissions if the emissions are close to the surface, and this yields a lower residual burden. 
Table 2. Global and annual mean aerosol lifetimes, burdens, and deposition rates in the GEOS-Chem simulation. Round brackets indicate relative contribution to total deposition. Dust bin radii range given in square brackets. Also shown are the global, 6-month mean ${ }^{137} \mathrm{Cs}$ lifetime $\left(\tau_{6 m o}\right)$, burden, and deposition rates for the four simulations of this study described in Table 1 .

\begin{tabular}{|c|c|c|c|c|}
\hline Aerosol species & Lifetime [days] & Burden $[\mathrm{Tg}]$ & Wet deposition $\left[\mathrm{Tg} \mathrm{yr}^{-1}\right]$ & Dry deposition $\left[\operatorname{Tg~yr}^{-1}\right]$ \\
\hline Black carbon & 6.1 & 0.12 & $5.65(82 \%)$ & $1.23(18 \%)$ \\
\hline Organic carbon & 5.9 & 0.63 & $33.0(85 \%)$ & $5.75(15 \%)$ \\
\hline Sulfate-nitrate-ammonium & 2.6 & 1.1 & $152(97 \%)$ & $4.2(3 \%)$ \\
\hline Dust (total) & 5.8 & 19.7 & $731(61 \%)$ & $476(39 \%)$ \\
\hline Dust $[0.1-1.0 \mu \mathrm{m}]$ & 9.3 & 3.9 & $143(92 \%)$ & $12.8(8 \%)$ \\
\hline Dust $[1.0-1.8 \mu \mathrm{m}]$ & 8.2 & 7.1 & $262(82 \%)$ & $58.9(28 \%)$ \\
\hline Dust $[1.8-3.0 \mu \mathrm{m}]$ & 6.1 & 6.7 & $242(60 \%)$ & $162(40 \%)$ \\
\hline Dust $[3.0-6.0 \mu \mathrm{m}]$ & 2.1 & 2.1 & $119(32 \%)$ & $252(68 \%)$ \\
\hline Sea salt (total) & 0.4 & 4.0 & $2250(65 \%)$ & $1190(35 \%)$ \\
\hline Sea salt (accumulation) & 1.2 & 0.18 & $54.5(96 \%)$ & $2.0(4 \%)$ \\
\hline Sea salt (coarse) & 0.4 & 3.8 & $2200(65 \%)$ & $1190(35 \%)$ \\
\hline Total (aerosols) & 1.9 & 25.6 & $3170(65 \%)$ & $1680(35 \%)$ \\
\hline Radionuclide & [days] & {$[\mathrm{PBq}]$} & {$\left[\mathrm{GBq} \mathrm{s}^{-1}\right]$} & {$\left[\mathrm{GBq} \mathrm{s}^{-1}\right]$} \\
\hline${ }^{137} \mathrm{Cs}$ CTL & 1.8 & 0.372 & $2.07(85 \%)$ & $0.37(15 \%)$ \\
\hline${ }^{137} \mathrm{Cs}$ USFC & 3.9 & 0.825 & $1.96(81 \%)$ & $0.44(19 \%)$ \\
\hline${ }^{137}$ Cs U5K & 14.7 & 3.11 & $2.17(89 \%)$ & $0.27(11 \%)$ \\
\hline${ }^{137} \mathrm{Cs}$ U7K & 21.1 & 4.45 & $2.17(89 \%)$ & $0.26(11 \%)$ \\
\hline
\end{tabular}

Figure 3 shows the instantaneous lifetimes for the aerosolbound global ${ }^{137} \mathrm{Cs}$ burden. For simulations CTL and USFC, instantaneous lifetimes are short (less than 5 days) during the initial period after emissions before transport into the free troposphere. Simulation CTL has the lowest instantaneous lifetimes during the first two weeks due to a combination of dry deposition near the source and wet scavenging by rain events near the accident site as described in Stohl et al. (2012). The majority of ${ }^{137} \mathrm{Cs}$ mass is removed during this time period and yields a 6-month mean lifetime of about 2 days. After the ${ }^{137}$ Cs has a quasi-steady-state gradient of concentration in the Northern Hemisphere (after about day 40 following 11 March 2011 for simulation CTL and day 20 for USFC, U5K, and U7K), the instantaneous lifetimes exhibit a steady increase. Ongoing mixing to regions with longer residence times particularly, mixing into the stratosphere yields the steady increase.

Figure 3 shows that for simulation USFC, the instantaneous lifetimes during the first two weeks are in the range of 3-10 days. The 6-month mean lifetime for the global burden (which is strongly controlled by the major mass losses in the first few days after emissions) is about 3.9 days. Indeed, for any aerosol species with emissions into the boundary layer, the global mean lifetime is similarly and strongly controlled by the removal that happens in the first few days before the aerosols leave the boundary layer and enter the free troposphere. Thus, global models typically have global mean aerosol lifetimes of 3-7 days (Benkovitz et al., 2004; Textor et al., 2006), quite similar to that for the ${ }^{137} \mathrm{Cs}$ in simulation USFC.
The global and annual mean lifetimes for the aerosol species in the GEOS-Chem simulation are shown in Table 2 . These aerosols are simulated using the same removal schemes as for the radionuclide simulation. The global, annual mean lifetimes of the carbonaceous aerosols and dust are about 6 days, which is close to the mean lifetime of ${ }^{137} \mathrm{Cs}$ when injected uniformly into the surface layer (simulation USFC). A shorter black carbon (BC) lifetime (4.2 days) in the recent GEOS-Chem simulation of Wang et al. (2014) is attributed to their modified impaction scavenging of hydrophobic BC in convective updrafts and scavenging of hydrophilic BC in ice clouds. The sulfate-nitrate-ammonium system has a shorter lifetime, 2.6 days. In-cloud production of sulfate that is often coincident with precipitation contributes to this lower lifetime. Sea salt has the shortest lifetime ( 0.4 days) due to the rapid dry deposition of the coarse mode after emission and the peak sea-salt emissions in the storm-track regions of the oceans with frequent precipitation. The 1.8-day mean lifetime for ${ }^{137} \mathrm{Cs}$ for simulation CTL is lower than for the aerosols (except sea salt, which is mostly in the coarse mode). The rapid removal by precipitation events near the source contributes to this lower ${ }^{137} \mathrm{Cs}$ lifetime. Table 2 also shows that about $85 \%$ of the ${ }^{137} \mathrm{Cs}$ removal is attributed to wet deposition. This fraction is about $97 \%$ for the sulfate-nitrate-ammonium system, $90 \%$ for the carbonaceous aerosols, $65 \%$ for sea salt and $60 \%$ for dust. Thus, these lifetimes are strongly controlled by wet deposition.

Figure 3 also shows instantaneous lifetimes of about 100 days in the first few days after emission for simulation U7K (about 30 days for U5K), which yields a 6-month mean lifetime of 21.1 days for simulation U7K (14.7 days for U5K). 


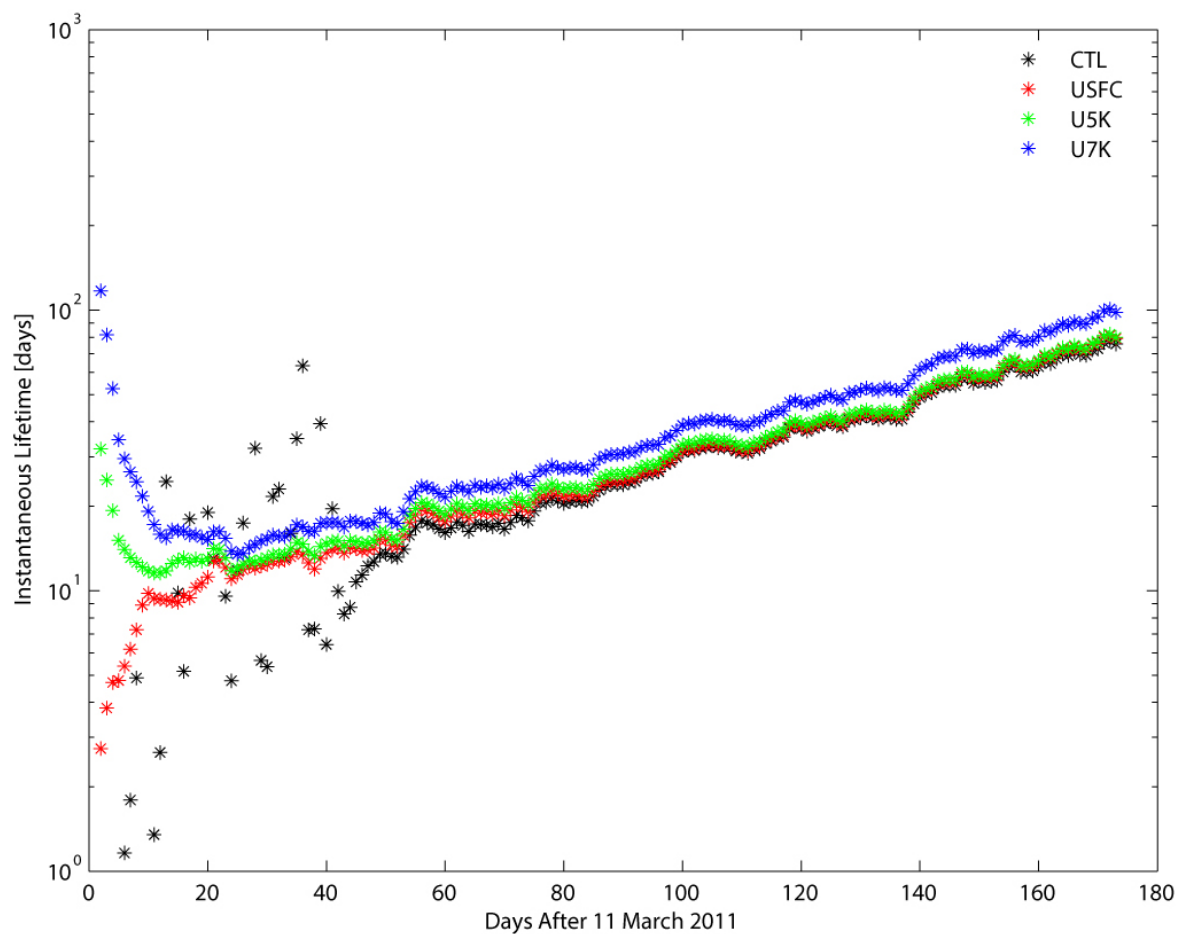

Fig. 3. Instantaneous lifetime ( $\tau_{\text {instant }}$ ) of the global ${ }^{137} \mathrm{Cs}$ burden calculated with Eq. (5), for the four GEOS-Chem simulations of this study described in Table 1.

After about 3 weeks, there is a quasi-steady-state gradient of concentration through the troposphere with mixing into the boundary layer. At this point for simulations U5K and $\mathrm{U} 7 \mathrm{~K}$, the removal becomes more efficient, with minimum instantaneous lifetimes of about 10 days, similar to simulation USFC. Thus, there is a strong divergence in the instantaneous lifetimes between our four simulations for the first three weeks of the simulations. However, after three weeks, the instantaneous lifetimes converge for the three sensitivity simulations. The convergence occurs later for simulation CTL due to the ongoing emissions over about 40 days. Thereafter, the instantaneous lifetimes increase with time and are similar (within 10-20\%) in magnitude for all simulations. This is due to the similar nature of the ongoing removal and mixing processes after the radionuclides have a quasi-steadystate gradient of concentration through the troposphere.

Since the instantaneous lifetimes are not constant, the time period chosen for the e-folding fit will strongly influence the calculated e-folding times. We chose days 20 to 80 after the onset of emissions for the fit since this allowed a direct comparison with the measurement e-folding times reported by Kristiansen et al. (2012). The e-folding times of the global burden shown on Fig. 2 range from 14.1 to 19.0 days for simulations USFC and U7K, respectively. This is a smaller range than for the mean lifetimes. Injection heights above the boundary layer increase the e-folding times by $30 \%$ for the chosen fit period (simulations $\mathrm{U} 5 \mathrm{~K}$ and $\mathrm{U} 7 \mathrm{~K}$ relative to simulations CTL and USFC).

\subsection{Site-specific lifetimes}

Table 3 gives the ${ }^{137} \mathrm{Cs}$ to ${ }^{133} \mathrm{Xe}$ surface layer concentration ratio e-folding times for our simulations (fit over days 20 to 80 of the simulation) and also shows the e-folding times presented by Kristiansen et al. (2012) based on measured surface layer activity concentrations over the same time period. We focus on the ratio of ${ }^{137} \mathrm{Cs}$ to ${ }^{133} \mathrm{Xe}$ for consistency with their approach and to remove the influence of transport into the stratosphere and Southern Hemisphere as described in Kristiansen et al. (2012). The e-folding times for all of these sites generally represent air that has left the boundary layer and been transported through the free troposphere. Thus, these e-folding times are not strongly influenced by the quick removal of mass that occurs in the boundary layer near the emissions source, in contrast with the global, 6-month mean lifetimes. The e-folding time combining all sites together is 16.7 days for simulation CTL, which is $20 \%$ longer than that reported for the measurements (13.9 days). Errors in the removal or transport parameterizations in our model may contribute to these differences. However, our results differ from the factor-of-two underestimation in global model lifetimes, suggested by Kristiansen et al. (2012). For simulation CTL, the surface layer concentration e-folding time for the sites combined is also about $20 \%$ longer than the simulated global 

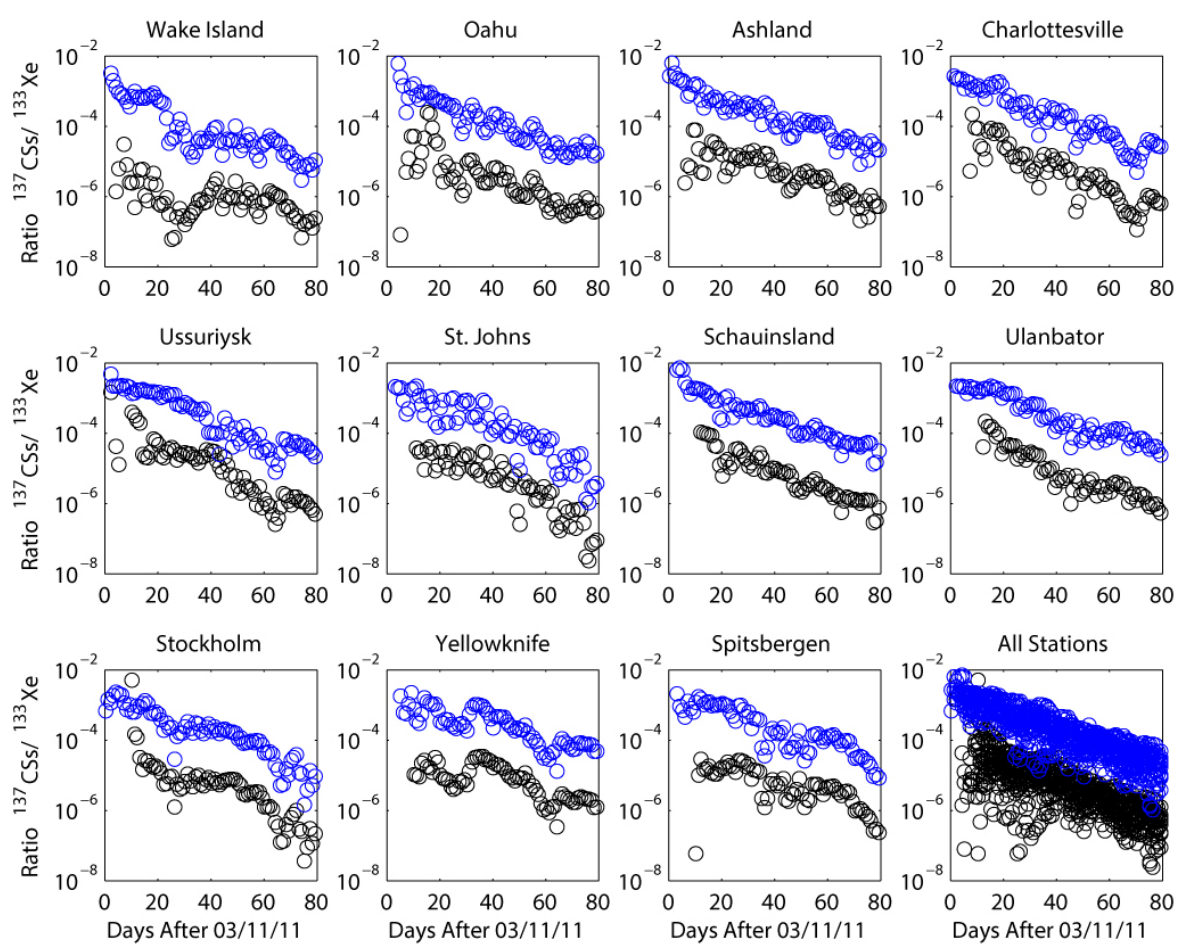

Fig. 4. Surface layer ${ }^{137} \mathrm{Cs} /{ }^{133} \mathrm{Xe}$ activity concentration ratio for the GEOS-Chem simulations CTL (black) and U7K (blue) as described in Table 1. The e-folding times and station latitude and longitude are shown in Table 3.

Table 3. Surface layer activity concentration ratio $\left({ }^{137} \mathrm{Cs} /{ }^{133} \mathrm{Xe}\right)$ e-folding times $\left(\tau_{e}\right)$ in days derived from measurements $(\mathrm{Kristiansen}$ et al., 2012) (square brackets indicate $95 \%$ confidence interval) and for the four simulations of this study described in Table 1.

\begin{tabular}{lcrcccccc}
\hline Site name & Latitude & Longitude & Altitude $[\mathrm{m}]$ & Measurements & CTL & USFC & U5K & U7K \\
\hline Wake Island* & 19.3 & 166.6 & 5 & $8.8[6.6,13.9]$ & 17.9 & 15.8 & 16.8 & 18.4 \\
Oahu & 21.5 & -158.0 & 250 & $9.6[7.7,12.9]$ & 19.7 & 15.8 & 16.6 & 17.6 \\
Ashland & 37.2 & -99.8 & 600 & $18.1[13.6,27.2]$ & 16.5 & 16.6 & 17.1 & 18.3 \\
Charlottesville & 38.0 & -78.4 & 250 & $15.7[12.2,22.0]$ & 14.5 & 14.5 & 14.9 & 16.4 \\
Ussuriysk & 44.2 & 132.0 & 50 & $14.1[8.4,47.6]$ & 12.4 & 12.7 & 13.0 & 14.3 \\
St John's & 47.6 & -52.7 & 130 & $14.3[11.0,20.8]$ & 10.1 & 9.8 & 9.9 & 10.9 \\
Shauinsland & 47.9 & 7.9 & 270 & $16.2[12.6,22.6]$ & 15.9 & 15.2 & 16.1 & 17.7 \\
Ulan-Bator & 47.9 & 106.3 & 1340 & $8.8[7.4,10.8]$ & 15.7 & 15.2 & 15.9 & 17.8 \\
Stockholm & 59.2 & 17.6 & 50 & $15.3[11.0,25.1]$ & 13.9 & 13.4 & 13.7 & 15.1 \\
Yellowknife & 62.5 & -114.5 & 200 & $13.1[11.7,14.9]$ & 22.6 & 17.3 & 18.3 & 21.9 \\
Spitsbergen & 78.2 & 15.4 & 500 & $15.1[12.3,19.4]$ & 18.8 & 15.9 & 17.4 & 20.1 \\
All sites & & & & $13.9[12.8,15.2]$ & 16.7 & 15.0 & 15.4 & 16.8 \\
\hline
\end{tabular}

* Wake Island e-folding time fit over days 40 to 80 after onset of emissions, remaining sites fit over days 20 to 80 .

burden e-folding time of 14.1 days. This slight difference in the e-folding time for the simulated global burden relative to the site-mean arises since the geographic distribution of the CTBTO sites will not yield an exact representation of the global mean.

Table 3 shows that for the mid-latitudes sites, the simulated e-folding times agree closely with the measurements, but with a consistent underestimation of the measurements of about $10 \%$. For the tropical sites (Oahu and Wake Island), the e-folding times are overestimated by about a factor of two relative to the measurements. Possible explanations are errors in simulating convective scavenging, convective transport, mixing from the free troposphere to the marine boundary layer, or assuming that ${ }^{137} \mathrm{Cs}$ attaches only to sulfate and neglecting coagulation with larger aerosols. For Wake Island, the e-folding time was fit over days 40-80 since the simulated concentration ratios did not exhibit a steady decrease until after day 40. For the mountainous Ulan-Bator site, the 
model also overestimates the e-folding time. This site may be influenced by orographic precipitation (Kristiansen et al., 2012) at scales finer than the GEOS-Chem horizontal resolution.

Table 3 also shows that the e-folding times at the surface sites are similar (within 10-30\%) for all the simulations. The emission injection farthest outside of the boundary layer yields e-folding times that are longest by about $30 \%$ (simulation U7K with respect to CTL and USFC). Thus, the simulated e-folding times do not depend very much on the exact model set-up for the emission parameters, including altitude, location and time. This has an important implication for the application of this radionuclide measurement-based constraint on simulated lifetimes. Since the simulated e-folding times are relatively insensitive to the uncertainties related to the emissions, the e-folding times derived from measurements provide a very robust constraint on modeled lifetimes provided the comparisons are carefully made at the same locations and times and after the radionuclides have reached a quasi-steady-state gradient of concentration.

Figure 4 shows the simulated radionuclide concentration ratios at each of the 11 CTBTO sites for the 6-month period after the earthquake for the simulations CTL and U7K. For the CTL simulation, the concentration ratios at these sites peak after 10-20 days. Thus, the e-folding fitting time was chosen to start at day 20 similar to Kristiansen et al. (2012). The ratios for simulation U7K show an initially slower decay over the first 20 days of the simulation at these sites. After day 20 , the radionuclides have a quasi-steady-state gradient of concentration in the troposphere for both simulations and the decay rates become quite similar. However, the residual concentration ratios after 6 months differ by more than an order of magnitude and increase with injection height, similar to our findings for the global burden.

\subsection{Dependence of simulated burden and lifetime vertical profiles on altitude and location}

Figure 5 shows the vertical profile of the Northern Hemisphere zonal layer-mean ${ }^{137} \mathrm{Cs}$ burden for the simulation USFC over the final four months of the 6-month simulation. For this time period the ${ }^{137} \mathrm{Cs}$ has a quasi-steady-state gradient of concentration throughout the Northern Hemisphere with concentrations increasing with altitude. The ${ }^{137} \mathrm{Cs}$ has a maximum in the Northern Hemisphere upper troposphere/stratosphere since this is the region of least efficient removal. About $40 \%$ of the global mean ${ }^{137} \mathrm{Cs}$ burden over the final four months of the simulation resides in the stratosphere. The fraction of the global monthly mean ${ }^{137} \mathrm{Cs}$ burden in the stratosphere is $28 \%, 42 \%, 53 \%$, and $64 \%$ for May, June, July and August, respectively. Since removal from the stratosphere is inefficient, this drives the increase in instantaneous lifetimes shown in Fig. 3. Simulated aerosol burdens as a function of tracer age have also been shown to exhibit a similar increase in mass fraction in the upper tropo-
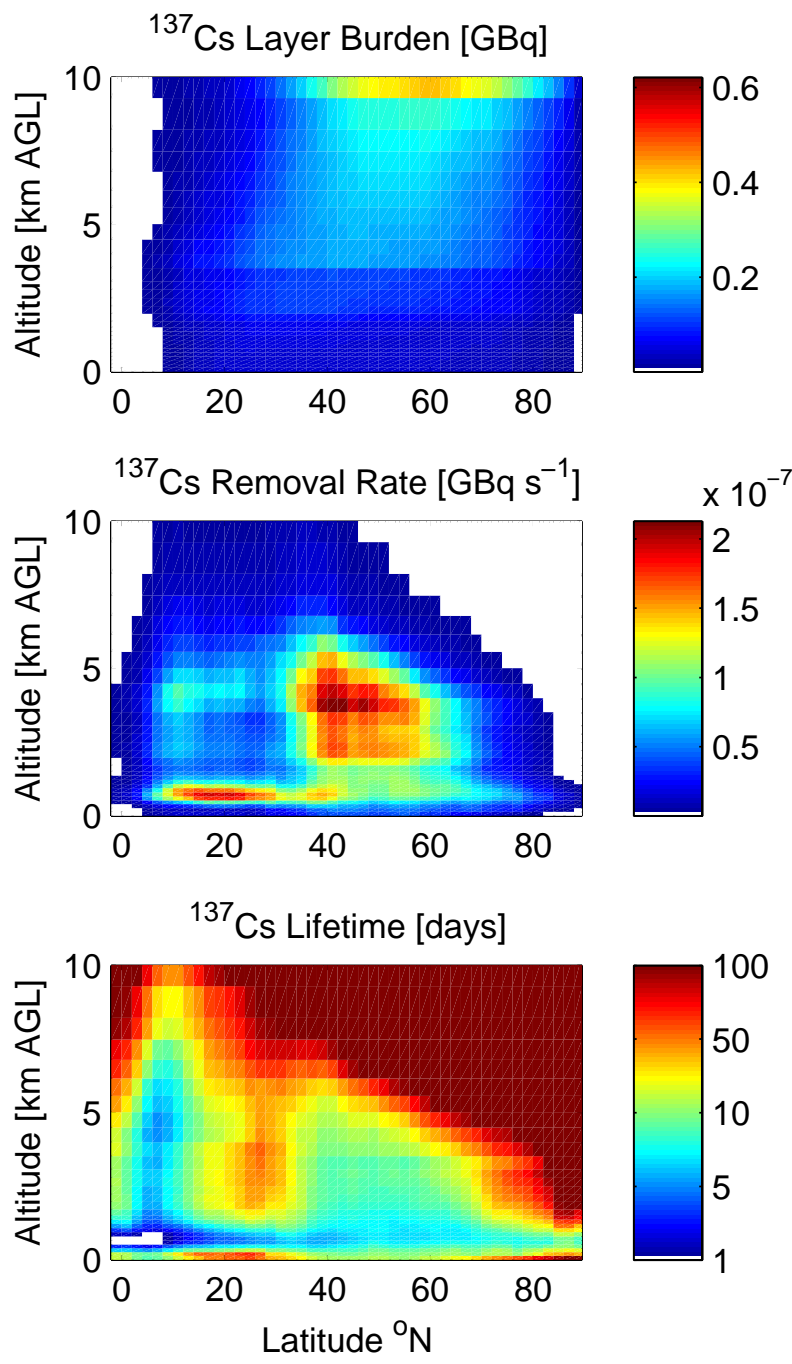

Fig. 5. Zonal, 4-month mean ${ }^{137} \mathrm{Cs}$ layer burdens (top panel), zonal, 4-month mean ${ }^{137} \mathrm{Cs}$ wet removal rates (middle panel), and zonal, 4-month mean ${ }^{137} \mathrm{Cs}$ lifetimes $\left(\tau_{4 \mathrm{mo}}\right)$ with respect to wet deposition (bottom panel). All zonal means are taken over the final four months of the simulation USFC.

sphere and stratosphere (Cassiani et al., 2013). Figure 5 also shows the vertical profile of the ${ }^{137} \mathrm{Cs} 4$-month mean wet removal rates. Maximum removal rates occur between 2 and $6 \mathrm{~km}$ in the mid-latitudes and in the tropics at about $1 \mathrm{~km}$. The initial quick removal rates following the emissions into the surface layer are excluded since the mean is for the last four months of the simulation.

The bottom panel of Fig. 5 shows the vertical profile of the 4-month and layer-mean ${ }^{137} \mathrm{Cs}$ lifetimes with respect to wet removal. Lifetimes are lowest and less than 5 days in the boundary layer below $2 \mathrm{~km}$. Lifetimes generally increase (by several orders of magnitude) with altitude since wet removal mechanisms become increasingly less efficient with altitude. This is similar to the result of Giorgi and Chameides (1986) who found order-of-magnitude differences in global 

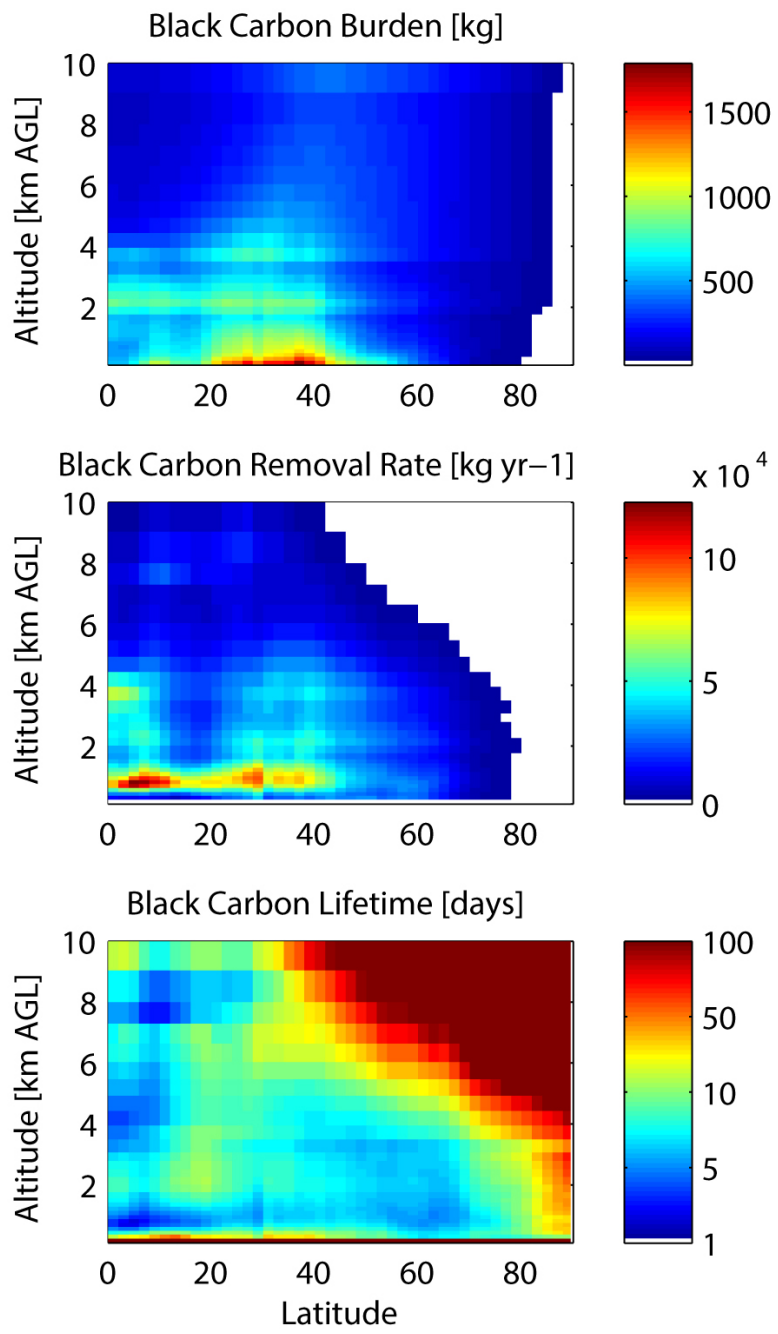

Fig. 6. Zonal, annual mean black carbon layer burdens (top panel), zonal, annual mean black carbon wet removal rates (middle panel), zonal, annual mean black carbon lifetimes with respect to wet deposition (bottom panel) for the standard GEOS-Chem aerosol simulation

mean lifetimes between the surface layer and $8 \mathrm{~km}$. The minimum in the lifetimes has a greater vertical extent in the tropics (lifetimes are less than 5 days below $6 \mathrm{~km}$ ) and in the mid-latitudes. Wet removal is less in the subtropics and in the polar regions and this yields a relative maximum in the lifetimes in the layers between 2 and $6 \mathrm{~km}$. We emphasize that the actual lifetime of a particle at a given location is not necessarily the same as what is shown in this figure since these lifetimes with respect to wet removal neglect the influence of advection. In general, the lifetimes of particles in the slowremoval parts of the atmosphere (e.g. upper troposphere and at high latitudes) can be shorter than what this figure shows since particles can move out of these regions.

These location-dependent lifetimes shown in Fig. 5 are similar for all four simulations for the final four months of the simulation (not shown). After the radionuclides have a quasisteady-state gradient of concentration in the troposphere, the location-dependent lifetime is independent of the initial locations of the injection, although the magnitude of the 4-month mean burdens and removal rates are different between the four simulations. Figure 3 also illustrated that once the particles move all away from the $5 \mathrm{~km}$ and $7 \mathrm{~km}$ injection altitude (after the initial few days), the instantaneous lifetimes decrease and the overall mean lifetime is less than the 100 days implied by the initial losses before the influence of advection.

The preceding figures illustrated that the mean lifetime of aerosol-bound ${ }^{137} \mathrm{Cs}$ depends strongly on where the aerosol is located in the troposphere in terms of altitude and geographic location. As a result, e-folding times at sites remote to a source do not reflect global mean lifetimes for species emitted into the boundary layer, which is controlled by initial quick removal after emission. Mean lifetimes and e-folding times would only be the same for species emitted into the boundary layer if they stayed in the boundary layer and did not undergo any vertical mixing into the free troposphere where lifetimes are significantly longer.

Figure 6 shows the vertical profiles of the zonal and annual mean layer burden, wet removal rates and lifetimes with respect to wet removal for one of the aerosol species in the GEOS-Chem model, black carbon. The near-surface maximum in the mean layer burden in the tropics/subtropics is associated with biomass burning sources. The maximum in the wet removal rates occurs in the boundary layer close to the burden maxima. The minima of less than 5 days in the black carbon lifetime with respect to wet deposition has the same spatial distribution as for the ${ }^{137} \mathrm{Cs}$, with minima in the midlatitude storm tracks and regions of convection in the tropics. Similar profiles are seen for the other aerosol species (not shown) with differences due to the different relative contributions of wet and dry removal to the total removal rates for the different aerosol species. These differences in relative contributions of wet and dry removal prevent an apples-to-apples comparison between the vertical profiles of the lifetimes of any aerosol species and ${ }^{137} \mathrm{Cs}$, but we can see similarities under the same wet scavenging scheme.

\section{Conclusions}

In this study, we used the GEOS-Chem model to interpret lifetimes of aerosol-bound radionuclides emitted after the Fukushima Daiichi nuclear power plant (FD-NPP) accident of March 2011. The ${ }^{137} \mathrm{Cs}$ lifetimes have implications for understanding aerosol lifetimes since ${ }^{137} \mathrm{Cs}$ immediately attaches to aerosols upon emission to the atmosphere. Aerosol lifetimes and removal processes are poorly constrained in present-generation global models (Textor et al., 2006), and as a result the constraints given by ${ }^{137} \mathrm{Cs}$ measurements are valuable. We found a 1.8-day mean lifetime of the global ${ }^{137} \mathrm{Cs}$ burden for our simulation of the FD-NPP accident 
using the emissions data set of Stohl et al. (2012). However, an exponential fit over days 20-80 after the onset of emissions yielded an e-folding time of 14.1 days for the simulated global burden and 16.7 days for the site-mean of the simulated surface layer ${ }^{137} \mathrm{Cs} /{ }^{133} \mathrm{Xe}$ concentration ratios at 11 Comprehensive Nuclear Test-Ban Treaty Organization (CTBTO) sites. This is at the upper end of the 10.0-13.9 days range of the e-folding times for measurements of surfacelayer ${ }^{137} \mathrm{Cs} /{ }^{133} \mathrm{Xe}$ concentration ratios during this time at the same CTBTO sites (Kristiansen et al., 2012).

The study by Kristiansen et al. (2012) suggested that the e-folding times based on CTBTO measurement data may indicate that global models with mean aerosol lifetimes of 3-7 days underestimate aerosol lifetimes by as much as a factor of two. However, we found that the site-mean e-folding times for the GEOS-Chem model and the measurements agree within $30 \%$, whereas the simulated global 6-month mean ${ }^{137} \mathrm{Cs}$ lifetime differed from simulated e-folding times by about one order of magnitude. Thus, mean lifetimes and e-folding times are not directly comparable.

We examined the reasons for this difference between mean lifetimes and e-folding times. Mean lifetimes strongly depend on the location and altitude of the radionuclide injection. We showed that for simulated injections into the boundary layer, the majority of the mass is removed within the first few days and this yielded mean lifetimes of only a few days. The mean lifetime for ${ }^{137} \mathrm{Cs}$ for our control simulation with the emissions data set of Stohl et al. (2012) was lower than typical aerosol mean lifetimes of 3-7 days in global models due to the fast removal of aerosols by precipitation events near the emission site that were coincident with the periods of strongest emissions. Both global mean aerosol lifetimes and ${ }^{137} \mathrm{Cs}$ mean lifetimes are strongly controlled by this rapid removal that occurs in the boundary layer prior to mixing into the free troposphere.

Our sensitivity simulations with instantaneous injections into layers at $5 \mathrm{~km}$ and $7 \mathrm{~km}$ yielded mean lifetimes of 14.7 days and 21.1 days, respectively. These mean lifetimes were longer than for boundary layer injections due to slower removal in the first few days after emissions until the radionuclides have a quasi-steady-state gradient of concentration in the Northern Hemisphere troposphere with mixture between the free troposphere and boundary layer. We found that the simulated e-folding times were relatively insensitive to emission parameters (altitude, location and time). This implies that despite uncertainties in emission parameters, the measurement-based e-folding times provide a very robust constraint on simulated e-folding times provided that the comparisons are carefully conducted at the same locations and times and after the radionuclides have reached a quasisteady-state gradient of concentration. A more detailed comparison of this type will be the topic of a future manuscript.

E-folding times based on fits over days 20-80 after the onset of emissions exclude the influence of the initial rapid removal of the majority of mass that occurs for a boundary layer injection. A fit taken over only the first few days after a pulse emission would yield a lifetime close to the mean lifetime. However, a fit taken after a period of mixing into the free troposphere (days 20-80) was shown to yield e-folding times in the range of 10 to 20 days. We found that the decrease of the global ${ }^{137} \mathrm{Cs}$ burden for our simulations was not perfectly exponential since the instantaneous e-folding times between adjacent timesteps changed due to ongoing mixing into regions where removal is less efficient such as the stratosphere. As a result, exponential fits are strongly sensitive to the period of time taken for the fit.

These results have implications for the interpretation of the aerosol lifetime constraint provided by an exponential fit to measurement data at sites remote to the emissions. The aerosol mean lifetimes and the radionuclide e-folding times (remote to emission site and after the majority of the emission pulse has ended) cannot be directly compared since the e-folding times exclude the influence of the initial rapid removal in the boundary layer unlike the former. A uniform Northern Hemisphere surface layer ${ }^{137} \mathrm{Cs}$ injection simulation, which had a mean lifetime of 5.3 days (global burden e-folding time of 15.3 days) can be considered a closer surrogate to global mean aerosol lifetime.

A site-by-site comparison of our simulated to the measurement (Kristiansen et al., 2012) surface layer ${ }^{137} \mathrm{Cs} /{ }^{133} \mathrm{Xe}$ ratio e-folding times showed overestimations as large as a factor of two at tropical and high-latitude sites, and a tendency for the simulated results to be $10-30 \%$ lower than the measurement e-folding times at the mid-latitude sites. This suggests the possible need for improvements in the model transport and scavenging parameterizations, possible issues with comparison with sites at a sub-grid scale level, and possible deficiencies in representing ${ }^{137} \mathrm{Cs}$ removal (i.e. that it has the same removal efficiencies as accumulation mode sulfate). Further investigation is warranted.

We examined zonal mean profiles of ${ }^{137} \mathrm{Cs}$ lifetimes with respect to wet removal considering the final four months of our six month simulations in order to eliminate the influence of the initial, quick boundary layer removal. These profiles were independent of the initial altitude of the radionuclide injection, although layer burden and wet deposition rates are strongly dependent of the injection altitude. There was also a strong altitude and latitude dependence of these lifetimes. Lifetimes were generally 5 days and shorter in the boundary layer below $2 \mathrm{~km}$. In the tropics and mid-latitudes these shorter lifetimes extended up to $6 \mathrm{~km}$ (due scavenging to convective towers and mid-latitude storms). Lifetimes generally decrease strongly with altitude in the free troposphere (by a few orders of magnitude). These lifetimes were 50 days or more in the high latitudes and in the subtropics where there is less efficient wet removal. Aerosol lifetimes in the GEOSChem simulation behaved similarly. 
Parameterizations for aerosol removal processes (dry and wet deposition) contribute strongly to differences in threedimension aerosol concentrations predicted by global models (Textor et al., 2006). Simulations of aerosol-bound radionuclide concentrations after an emission pulse, such as for the Fukushima Daiichi nuclear power plant accident, provide an instructive opportunity to characterize the diversity in transport and removal between global models and will be the subject of a future model intercomparison study proposed by Kristiansen et al. (2012). Future model-measurement intercomparisons should also examine the sensitivity of ${ }^{137} \mathrm{Cs}$ removal to assumptions about the type of aerosol to which it attaches.

There is an ongoing need for the development of data sets to provide constraints on aerosol removal processes (measurements of radionuclide and aerosol concentrations and deposition). Radionuclide measurements provide one of the most valuable constraints on aerosol wet removal available for model-observation comparison. However, as a result of the tight connections between removal and mixing, the careful interpretation of measurement-based constraints is essential.

Acknowledgements. The authors thank the Atlantic Computational Excellence Network (ACENet) and NSERC for funding and computational resources. We thank the Preparatory Commission for the Comprehensive Nuclear-test-ban Treaty Organisation (CTBTO) for the provision of the data used in this paper. The views expressed are those of the authors and do not necessarily represent the views of the CTBTO Preparatory Commission. We thank S. E. Schwartz for helpful discussions. We also thank A. Stohl and N. Kristiansen for making available the ${ }^{137} \mathrm{Cs}$ and ${ }^{133} \mathrm{Xe}$ emission data sets used for this study.

Edited by: A. Nenes

\section{References}

Alexander, B., Park, R. J., Jacob, D. J., Li, Q. B., Yantosca, R. M., Savarino, J., Lee, C. C. W., and Thiemens, M. H.: Sulfate formation in sea-salt aerosols: Constraints from oxygen isotopes, J. Geophys. Res., 110, D10307, doi:10.1029/2004JD005659, 2005.

Allen, D. J., Pickering, K. E., and Molod, A.: An evaluation of deep convective mixing in the Goddard Chemical Transport Model using International Satellite Cloud Climatology Project cloud parameters, J. Geophys. Res., 102, 25467-25476, 1997.

Arakawa, A. and Schubert, W. H.: Interactions of cumulus cloud ensemble with the large-scale environment, J. Atmos. Sci., 31, 671-701, 1974.

Benkovitz, C. M., Schwartz, S. E., Jensen, M. P., Miller, M. A., Easter, R. C., and Bates, T. S.: Modeling atmospheric sulfur over the Northern Hemisphere during the Aerosol Characterization Experiment 2 experimental period, J. Geophys. Res., 109, D22207, doi:10.1029/2004JD004939, 2004.
Bey, I., Jacob, D. J., Logan, J. A., and Yantosca, R. M.: Asian chemical outflow to the Pacific in spring: Origins, pathways and budgets, J. Geophys. Res., 106, 23097-23113, 2001.

Cambray, R. S., Cawse, P. A., Garland, J. A., Gibson, J. A. B., Johnson, P., Lewis, G. N. J., Newton, D., Salmon, L., and Wade, B. O.: Observations on radioactivity from the Chernobyl accident, Nucl. Energy, 26, 77-101, 1987.

Cassiani, M., Stohl, A., and Eckhardt, S.: The dispersion characteristics of air pollution from the world's megacities, Atmos. Chem. Phys., 13, doi:10.5194/acp-13-9975-2013, 9975-9996, 2013.

Charlson, R. J., Schwartz, S. E., Hales, J. M., Cess, R. D., Coakley, J. A., Hansen, J. E., and Hofmann, D. J.: Climate forcing by anthropogenic aerosols., J. Geophys. Res., 255, 423-430, 1992.

Croft, B., Lohmann, U., Martin, R. V., Stier, P., Wurzler, S., Feichter, J., Posselt, R., and Ferrachat, S.: Aerosol size-dependent below-cloud scavenging by rain and snow in the ECHAM5HAM, Atmos. Chem. Phys., 9, 4653-4675, doi:10.5194/acp-94653-2009, 2009.

Croft, B., Lohmann, U., Martin, R. V., Stier, P., Wurzler, S., Feichter, J., Hoose, C., Heikkilä, U., van Donkelaar, A., and Ferrachat, S.: Influences of in-cloud aerosol scavenging parameterizations on aerosol concentrations and wet deposition in ECHAM5-HAM, Atmos. Phys. Chem., 10, 1511-1543, doi:10.5194/acp-10-1511-2010, 2010.

Croft, B., Pierce, J. R., Martin, R. V., Hoose, C., and Lohmann, U.: Uncertainty associated with convective wet removal of entrained aerosols in a global climate model, Atmos. Chem. Phys., 12, 10725-10748, doi:10.5194/acp-12-10725-2012, 2012.

Dockery, D. W., Pope III, C. A., Xu, X., Spengler, J. D., Ware, J. H., Fay, M. E., Ferris, B. G. ., and Speizer, F. E.: An association between air pollution and mortality in six U.S. Cities, N. Engl. J. Med., 329, 1753-1759, 1993.

Fairlie, T. D., Jacob, D. J., and Park, R. J.: The impact of transpacific transport of mineral dust in the United States, Atmos. Environ., 41, 1251-1266, 2007.

Fairlie, T. D., Jacob, D. J., Dibb, J. E., Alexander, B., Avery, M. A., van Donkelaar, A., and Zhang, L.: Impact of mineral dust on nitrate, sulfate, and ozone in transpacific Asian pollution plumes, Atmos. Chem. Phys., 10, 3999-4012, doi:10.5194/acp-10-39992010, 2010.

Giorgi, F. and Chameides, W. L.: Rainout lifetimes of highly soluble aerosols and gases as inferred from simulations with a general circulation model, J. Geophys. Res., 91, 14367-14376, 1986.

Henze, D. K., Seinfeld, J. H., Ng, N. L., Kroll, J. H., Fu, T.-M., Jacob, D. J., and Heald, C. L.: Global modeling of secondary organic aerosol formation from aromatic hydrocarbons: Highvs. low-yield pathways, Atmos. Chem. Phys., 8, 2405-2420, doi:10.5194/acp-8-2405-2008, 2008.

Jaeglé, L., Quinn, P. K., Bates, T., Alexander, B., and Lin, J.-T.: Global distribution of sea salt aerosols: New constraints from in situ and remote sensing observations, Atmos. Chem. Phys., 11, 3137-3157, doi:10.5194/acp-11-3137-2011, 2011.

Kaneyasu, N., Ohashi, H., Suzuki, F., Okuda, T., and Ikemori, F.: Sulfate aerosol as a potentail transport medium of radiocesium from the Fukushima nuclear accident, Environ. Sci. Technol., 46, 5720-5726, doi:10.1021/es204667h, 2012.

Kristiansen, N. I., Stohl, A., and Wotawa, G.: Atmospheric removal times of the aerosol-bound radionuclides ${ }^{137} \mathrm{Cs}$ and ${ }^{131}$ I measured after the Fukushima Dai-ichi nuclear accident - a con- 
straint for air quality and climate models, Atmos. Chem. Phys., 12, 10759-10769, doi:10.5194/acp-12-10759-2012, 2012.

Liao, H., Henze, D. K., Seinfeld, J. H., Wu, S., and Mickley, L. J.: Biogenic secondary organic aerosols over the United States: Comparison of climatological simulatins with observations, J. Geophys. Res., 112, D06201, doi:10.1029/2006JD007813, 2007.

Lin, S. J. and Rood, R. B.: Multidimensional flux form semiLagrangian transport, Mon. Weather Rev., 124, 2046-2068, 1996.

Liu, H., Jacob, D. J., Bey, I., and Yantosca, R. M.: Constraints from ${ }^{210} \mathrm{~Pb}$ and ${ }^{7} \mathrm{Be}$ on wet deposition and transport in a global threedimensional chemical tracer model driven by assimilated meteorolgical fields, J. Geophys. Res., 106, 12109-12128, 2001.

Lohmann, U. and Feichter, J.: Global indirect aerosol effects: A review, Atmos. Chem Phys., 5, 715-737, doi:10.5194/acp-5-7152005, 2005.

Moorthi, S. and Suarez, M. J.: Relaxed Arakawa-Schubert: A parameterization of moist convection for general circulation models, Mon. Weather Rev., 120, 137-160, 1992.

Park, R. J., Jacob, D. J., Chin, M., and Martin, R. V.: Sources of carbonaceous aerosols over the United States and implications for natural visibility, J. Geophys. Res., 109, D15204, doi:10.1029/2002JD003,190, 2003.

Park, R. J., Jacob, D. J., D., B., Yantosca, R. M., and Chin, M.: Natural and transboundary pollution influences on sulfate-nitrateammonium aerosols in the United States: Implications for policy, J. Geophys. Res., 109, D15204, doi:10.1029/2003JD004,473, 2004.

Pope III, C. A., Ezzati, M., and Dockery, D. W.: Fine-particulate air pollution and life expectancy in the United States, N. Engl. J. Med., 360, 376-386, 2009.

Rasch, P. J., Feitcher, J., Law, J., Mahowald, N., Penner, J., Benkovitz, C., Genthon, C., Giannakopoulos, C., Kasibhatla, P., Koch, D., Levy, H., Maki, T., Prather, M., Roberts, D. L., Roelefs, G.-J., Stevenson, D., Stockwell, Z., Taguchi, S., Kritz, M., Chipperfield, M., Baldocchi, D., McMurry, P., Barry, L., Balkanski, Y., Chatfield, R., Kjellstrom, E., Lawrence, M., Lee, H. N., Lelieveld, J., Noone, K. J., Seinfeld, J. H., Stenchikov, G., Schwartz, S., Walcek, C., and Williamson, D.: A comparison of scavenging and deposition processes in global models: Results from the WCRP Cambridge Workshop of 1995., Tellus, 52B, 1025-1056, 2000.
Schwartz, S. E.: Residence times in reservoirs under non-steadystate conditions: application to atmospheric $\mathrm{SO}_{2}$ and aerosol sulfate, Tellus, 31, 530-547, 1979.

Schwartz, S. E.: The Whitehouse effect - shortwave radiative forcing of climate by anthropogenic aerosols: an overview, J. Aerosol Sci, 27, 359-382, 1996.

Stohl, A., Seibert, P., Wotawa, G., Arnold, D., Burkhart, J. F., Eckhardt, S., Tapia, C., Vargas, A., and Yasunari, T. J.: Xenon133 and caesium-137 releases into the atmosphere from the Fukushima Dai-ichi nulclear power plant: determination of the source term, atmospheric dispersion, and deposition, Atmos. Chem. Phys., 12, 2313-2343, doi:10.5194/acp-12-2313-2012, 2012.

Textor, C., Schulz, M., Guibert, S., Kinne, S., Balkanski, Y., Bauer, S., Berntsen, T., Berglen, T., Boucher, O., Chin, M., Dentener, F., Easter, R., Fillmore, D., Ghan, S., Ginoux, P., Gong, S., Grini, A., Hendricks, J., Horowitz, L., Huang, P., Isaksen, I., Iversen, T., Kloster, S., Koch, D., Kirkevag, A., Kristjansson, J. E., Krol, M., Lauer, A., Lamarque, J., Liu, X., Montanaro, V., Myhre, G., Penner, J., Pitari, G., Reddy, S., Seland, O., Stier, P., Takemura, T., and Tie, X.: Analysis and quantification of the diversities of aerosol life cycles within AeroCom, Atmos. Chem. Phys., 6, 1777-1813, doi:10.5194/acp-11-3137-2006, 2006.

Twomey, S.: Aerosol, clouds, and radiation., Atmos. Environ., 25A, 2435-2442, 1991.

van Donkelaar, A., Martin, R. V., Brauer, M., Kahn, R., Levy, R., Verduzco, C., and Villeneuve, P.: Global estimates of exposure to fine particulate matter concentrations from satellite-based aerosol optical depth, Environ. Health Perspec., 118, 847-855, doi:10.1289/ehp.0901,623, 2010.

Wang, Q., Jacob, D. J., Mao, J., Leibensperger, E. M., Carouge, C. C., Sager, P. L., Kondo, Y., Jimenez, J. L., Cubison, M. J., and Doherty, S. J.: Sources of carbonaceous aerosols and deposited black carbon in the Arctic in winter-spring: implications for radiative forcing, Atmos. Chem. Phys., 11, 12453-12473, doi:10.5194/acp-11-12453-2011, 2011.

Wang, Q., Jacob, D. J., Spackman, J. R., Perring, A. E., Schwarz, J. P., Moteki, N., Marais, E. A., Ge, C., Wang, J., and Barrett, S. R. H.: Global budget and radiative forcing of black carbon aerosol: constraints from pole-to-pole (HIPPO) observations across the Pacific, J, Geophys. Res., 119, 1-12, doi:10.1002/2013JD020824, 2014. 